\title{
Trabeculectomy in a Black American glaucoma population
}

\author{
J. FREEDMAN, E. SHEN, AND M. AHRENS* \\ From the Downstate Medical Center, Kings County Hospital, Brooklyn, New York
}

Trabeculectomy as a surgical treatment for glaucoma has been popularized and there have been many reports on the results (Welsh, 1972; Watson and Barnett, 1973; Ridgway, Rubinstein, and Smith, 1972; Nesterov, Federova, and Batmanov, 1972; Thyer and Wilson, 1972). There is only one report, however, of the results of trabeculectomy in a totally Black glaucoma population. This was from South Africa (Welsh, 1972). The present paper reports the results of trabeculectomy in a Black American glaucoma population.

\section{Patients and methods}

Trabeculectomy, by the method described by Cairns (Iliff, 1944) and modified by Watson (Welsh, r 969), was performed on $5 \mathrm{I}$ Black patients who attended the Glaucoma Clinic at Kings County Hospital, Brooklyn, New York. The group consisted of 22 men and 29 women representing a total of 64 eyes. Trabeculectomy was performed on both eyes in 13 patients. The average age of the men was 53.9 years and of the women 59 years. In all cases surgery followed failure of medical control of the glaucoma, failure being judged by continuing field loss despite maximum medical therapy and diurnal curve studies.

Under local anaesthesia a limbal-based conjunctival flap was made in the superotemporal or superonasal quadrant of the eye, starting at the anterior edge of the superior rectus muscle. A superficial scleral flap $4 \times$ $4 \mathrm{~mm}$ was then made through two-thirds' thickness of sclera. A deep scleral flap $2 \mathrm{~mm}$ wide and $3 \mathrm{~mm}$ long was then removed. Both superficial and deep scleral flaps were extended into clear cornea. Removal of the deep scleral flap showed the scleral spur and underlying iris which comes forward to block the gap caused by the removal of the deep scleral flap. An iridectomy was performed by abscising the prolapsed iris. The superficial scleral flap was sutured back into place with four IO-O Ethilon edge-to-edge sutures in 60 per cent of patients. In the remainder the superficial scleral flap was left unsutured. The conjunctival flap was sutured with a running $6-0$ chromic gut suture.

\section{Results}

The average follow-up period for the 5 I patients was I9 months. Trabeculectomy was considered to be successful if the intraocular pressures were consistently below $20 \mathrm{mmHg}$ over the whole followup period. Sixteen eyes (25 per cent) needed

*Medical student on summer fellowship

Address for reprints: Dr J. Freedman, Department of Ophthalmology, Medical School, Hospital Street, Johannesburg 200I, South Africa antiglaucoma medication in addition to the surgery to control the intraocular pressure. Twelve patients received pilocarpine, epitrate, and acetazolamide; three received epitrate and pilocarpine; and one was controlled with epitrate and acetazolamide.

The patients were divided into four groups according to their preoperative pressures. In group $\mathrm{A}$ the preoperative pressures were less than $20 \mathrm{mmHg}$, in group B they were 20 to $29 \mathrm{mmHg}$, in group $\mathrm{C}$ they were 30 to $40 \mathrm{mmHg}$, and in group $\mathrm{D}$ they were more than $40 \mathrm{mmHg}$. In the three eyes in group A the pressure dropped by an average of $6 \mathrm{mmHg}$ after trabeculectomy. The success rate in 23 eyes in group B was 87 per cent. In group $\mathrm{C}$ ( 27 eyes) 85 per cent were controlled; and in group D (I I eyes) 8I per cent were controlled and the postoperative pressures were less than $20 \mathrm{mmHg}$.

Trabeculectomy in association with suturing of the superficial scleral flap was successful in all cases in group $\mathrm{A}$, in 52 per cent in group $\mathrm{B}$, in 38 per cent in group $\mathrm{C}$, and in 54 per cent in group $\mathrm{D}$. Thus overall in those patients controlled by trabeculectomy 60 per cent, or more than half, had the superficial scleral flap sutured. The remaining 40 per cent had successful trabeculectomies without suture of the superficial scleral flap.

A conjunctival drainage bleb was found in 85 per cent of the controlled eyes. Intraocular pressures unassociated with a conjunctival bleb were controlled in 15 per cent of eyes, all of which had had the superficial scleral flap sutured.

\section{MEDICATION}

Thirty-seven of the 64 eyes ( 57 per cent) needed no further medication after surgery to control intraocular pressure, and 16 of the 64 eyes (25 per cent) did need medication. Three eyes (4 per cent) needed further surgery. In one a Scheie procedure was carried out, in another a further trabeculectomy and, in the third, a posterior lip sclerectomy. The pressure in eight eyes was not controlled by further surgery or by medication. Tonographic pre- and postoperative studies on a random sample of 32 eyes showed a postoperative improvement in outflow in 78 per cent. There was no improvement in outflow in 6.25 per cent, and in 15.6 per cent the postoperative outflow was decreased. Of the eyes in which postoperative outflow improved, the super- 
ficial scleral flap had been sutured in 33 per cent and not sutured in 66 per cent.

\section{COMPLICATIONS}

The most serious intraoperative complication was buttonholing of the conjunctival flap in two patients. Postoperatively five patients developed hyphaemas, and, interestingly, in none had the superficial scleral flap been sutured. All hyphaemas cleared within five days. A scleral staphyloma developed in two patients, neither of whom had had the superficial scleral flap sutured.

Of 16 eyes ( 13 patients) followed up for less than six months, in which the average preoperative pressure had been $43 \mathrm{mmHg}$, I3 (8I per cent) had a postoperative pressure of less than $20 \mathrm{mmHg}$ without medication.

\section{Discussion}

Trabeculectomy controlled the intraocular pressure in 82 per cent of our totally Black glaucoma population. Of these, 57 per cent were controlled without further medication and 25 per cent needed further medication. Intraocular pressure was controlled after trabeculectomy in 65 per cent of a totally Black African group of glaucomatous patients (Welsh, 1972). The effectiveness of the operation seems to be due to subconjunctival drainage of aqueous, as 90 per cent of our patients in whom trabeculectomy was successful also had preoperative drainage blebs. However, some other drainage mechanism would also seem to be active, since the eyes in ro per cent of the successful cases of trabeculectomy did not have a functioning drainage bleb.

In about half the successful trabeculectomies the superficial scleral flap was sutured. It seems from our study that success does not depend on suturing. In 95 per cent of those cases in which the superficial flap was sutured a functioning drainage bleb was present. Interestingly, the postoperative hyphaemas occurred only in those eyes in which the superficial scleral flap had not been sutured.

The average drop in postoperative pressure was related to the preoperative pressure. When the preoperative pressure was greater than $40 \mathrm{mmHg}$ the average pressure drop was $28 \mathrm{mmHg}$. When the preoperative pressure was 30 to $40 \mathrm{mmHg}$ the average postoperative drop was $16 \mathrm{mmHg}$, and with preoperative pressures of 20 to $30 \mathrm{mmHg}$ the average drop in postoperative pressure was Io $\mathrm{mmHg}$. The reasons for failure in all the three cases of trabeculectomy that had to be reoperated on were identical: episcleral fibrosis over the superficial scleral flap was impeding any subconjunctival drainage.

Filtering blebs, when present, were diffuse and non-succulent, probably as a result of controlled aqueous outflow rendered by the presence of the superficial scleral flap. The success rate of 80 per cent in our series seems to be the highest among those for filtering operations reported in Black glaucoma populations. Iliff (1944) reported a success rate of 23 per cent with trephine operations and 50 per cent with iridencleisis. Welsh (1969) reported a success rate of 30 to 50 per cent with trephine and Scheie operations. Berson, Zauberman, Landau, and Blumenthal (1966), in a series of II9 African patients, reported a success rate of 39 per cent for trephines, 26 per cent for Scheie procedures, and 4 per cent for iridencleisis. In the only other reported study in which trabeculectomy was performed exclusively on a Black glaucoma population, Welsh (1972) had a success rate of 67 per cent.

From our results and those reported by Welsh (1972) it would seem that trabeculectomy is now the filtering procedure of choice in uncontrolled glaucoma occurring in Black people, irrespective of the preoperative intraocular pressure. The reason for the success of this procedure over others in Black people remains unknown.

\section{Summary}

Trabeculectomy was performed on 5 I Black patients with uncontrolled glaucoma. The operation was successful in 80 per cent of cases followed-up for an average of 18 months. Success seemed to be independent of whether the superficial scleral flap was or was not sutured, although subconjunctival drainage, as indicated by the appearance of a bleb, seemed to be the predominant mechanism whereby the procedure functioned. The success rate in this series is the highest reported for glaucoma filtering procedures in Black glaucoma populations. Trabeculectomy may now be the operation of choice in uncontrolled glaucoma occurring in Black patients.

\section{References}

Berson, D., zauberman, h., Landau, L., and blumenthal, M. (i966) Amer. F. Ophthal., 62, 509

ILIFF, C. E. (1944) Ibid., 33, I523

NESTEROV, A. P., FEderova, N. v., and BatManov, y. E. (1972) Brit. F. Ophthal., 56, 833

RIDGWAY, A. E. A., RUBINSTEIN, K., and SMITH, v. H. (I972) Ibid., 56, 5 I I

THYER, H. W., and WILSON, P. (1972) Ibid., 56, 37

WATSON, P. G., and BARNeTt, F. (1973) Amer. F. Ophthal., 79, 831

WELSH, N. H. (1969) S. Afr. med. F., 43, 298

(1972) Brit. F. Ophthal., 56, 32 